\title{
Electronically Controllable Quadrature Sinusoidal Oscillator Using VD-DIBAs
}

\author{
Kanhaiya Lal Pushkar \\ Department of Electronics and Communication Engineering, Maharaja Agrasen Institute of Technology, New Delhi, India \\ Email: klushkar17@gmail.com
}

How to cite this paper: Pushkar, K.L. (2018) Electronically Controllable Quadrature Sinusoidal Oscillator Using VD-DIBAs. Circuits and Systems, 9, 41-48. https://doi.org/10.4236/cs.2018.93004

Received: December 6, 2017

Accepted: March 12, 2018

Published: March 15, 2018

Copyright $\odot 2018$ by author and Scientific Research Publishing Inc. This work is licensed under the Creative Commons Attribution International License (CC BY 4.0).

http://creativecommons.org/licenses/by/4.0/

\begin{abstract}
A new voltage-mode quadrature sinusoidal oscillator (QSO) using two voltage differencing-differential input buffered amplifiers (VD-DIBAs) and only three passive components (two capacitors and a resistor) is presented. The proposed QSO circuit offers advantages of independent electronic control of both oscillation frequency and condition of oscillation, availability of two quadrature voltage outputs and low active and passive sensitivities. SPICE simulation results have been included using $0.35 \mu \mathrm{m}$ MIETEC technology to confirm the validity of the proposed QSO oscillator.
\end{abstract}

\section{Keywords}

Voltage Differencing-Differential Input Buffered Amplifier, Voltage-Mode, Quadrature Sinusoidal Oscillator

\section{Introduction}

Quadrature sinusoidal oscillators (QSOs) are important blocks in the synthesis of modern transceivers. A QSO provides two sinusoids with a $90^{\circ}$ phase difference. QSOs are useful in telecommunications for quadrature mixers and single sideband generators [1], in direct-conversion receivers, used for measurement purposes in vector generators and selective voltmeters [2]. Because of these applications number of QSOs has been realized employing different active building blocks in the open literature [3]-[8]. VD-DIBA is one of the active building blocks among the various active building blocks introduced in reference [9] which is emerging as a very flexible and versatile building block for analog signal processing/signal generation and has been used earlier for realizing a number of functions. VD-DIBA has been used in single resistance controlled oscillators, simulation of inductors, realization of active filters [10]-[17]. Recently VD-DIBA 
has also been used in the realization of QSO where independent electronic control of CO and FO is not available [18]. Therefore, the purpose of this paper is to propose a new QSO having electronic control of both CO and FO by separate transconductance of the VD-DIBAs. This property is very attractive for realizing current controlled oscillators as FO can be controlled independently without disturbing $\mathrm{CO}$, whereas the flexibility of being able to adjust $\mathrm{CO}$ independently is useful in amplitude stabilization. The proposed configuration also offers low active and passive sensitivities. The validity of proposed structure has been confirmed by SPICE simulation with $0.35 \mu \mathrm{m}$ MIETEC technology.

\section{The Proposed New Oscillator Configuration}

The symbolic notation and the equivalent circuit model of the VD-DIBA are shown in Figure 1(a) and Figure 1(b) respectively. The circuit model includes two controlled sources: the voltage source controlled by differential voltage $\left(V_{z}-V_{v}\right)$ with the unity voltage gain and the current source controlled by differential voltage $\left(V_{+}-V_{-}\right)$, with the transconductance $g_{m}$. The corresponding voltage-current relationship of input-output terminals of VD-DIBA can be expressed by the following matrix:

$$
\left(\begin{array}{c}
I_{+} \\
I_{-} \\
I_{z} \\
I_{v} \\
V_{w}
\end{array}\right)=\left(\begin{array}{ccccc}
0 & 0 & 0 & 0 & 0 \\
0 & 0 & 0 & 0 & 0 \\
g_{m} & -g_{m} & 0 & 0 & 0 \\
0 & 0 & 0 & 0 & 0 \\
0 & 0 & 1 & -1 & 0
\end{array}\right)\left(\begin{array}{c}
V_{+} \\
V_{-} \\
V_{z} \\
V_{v} \\
I_{w}
\end{array}\right) .
$$

A straight forward circuit analysis of the circuit of Figure 2 yields the following characteristic equation (CE):

$$
\text { CE: } s^{2} C_{1} C_{2}+s C_{1}\left(\frac{1}{R_{0}}-g_{m_{2}}\right)+\frac{g_{m_{1}}}{R_{0}}=0 .
$$

From Equation (2), the $\mathrm{CO}$ and $\mathrm{FO}$ are given by

$\mathrm{CO}:$

$$
\left(\frac{1}{R_{0}}-g_{m_{2}}\right) \leq 0
$$

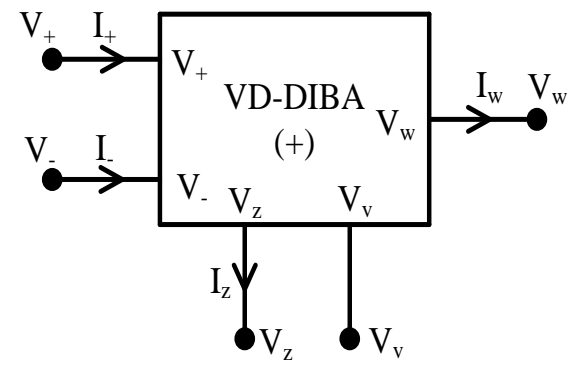

(a)

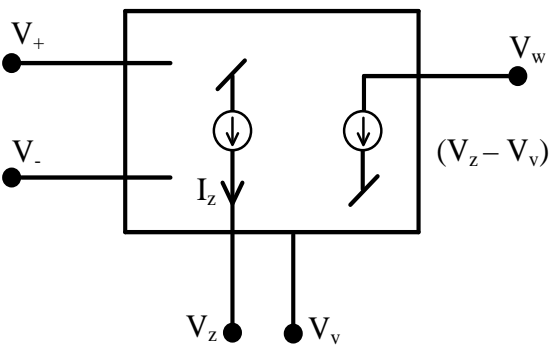

(b)

Figure 1. (a) Symbolic notation of; and (b) Equivalent circuit model of VD-DIBA. 


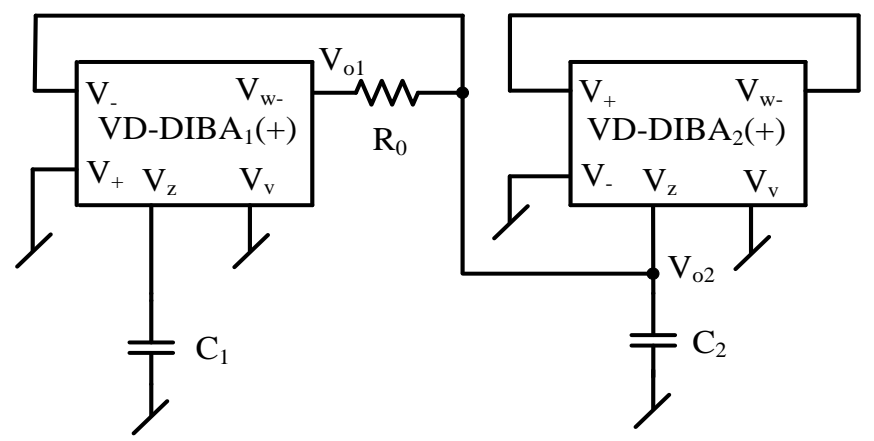

Figure2. Proposed electronically controllable quadrature sinusoidal oscillator.

FO:

$$
\omega_{0}=\sqrt{\frac{g_{m_{1}}}{R_{0} C_{1} C_{2}}} .
$$

Thus from Equations (3) and (4), it is clear that CO is electronically controllable by the transconductance $g_{m 2}$, whereas FO is electronically controllable through the transconductance $g_{m 1}$. Therefore both CO and FO are independently controllable by two separate transconductance of VD-DIBAs.

\section{Non-Ideal Analysis and Sensitivity Performance}

Considering $R_{Z}$ and $C_{Z}$ as parasitic resistance and parasitic capacitance respectively of the Z-terminal of the VD-DIBA, taking the non-idealities into account, namely the voltage of W-terminal $V_{W}=\left(\beta^{+} V_{Z}-\beta^{-} V_{V}\right)$ where $\beta^{+}=1-\varepsilon_{p}$ $\left(\varepsilon_{p} \ll 1\right)$ and $\beta^{-}=1-\varepsilon_{n}\left(\varepsilon_{n} \ll 1\right)$ denote the voltage tracking errors of $Z$-terminal and $\mathrm{V}$-terminal of the VD-DIBA respectively, then the expressions for $\mathrm{CE}, \mathrm{CO}$ and $\mathrm{FO}$ can be given as:

CE:

$$
\begin{aligned}
& s^{2}\left(C_{1}+C_{z}\right)\left(C_{2}+C_{z}\right)+s\left\{\left(C_{1}+C_{z}\right)\left(\frac{1}{R_{0}}+\frac{1}{R_{z}}-g_{m_{2}} \beta^{+}\right)+\frac{1}{R_{z}}\left(C_{2}+C_{z}\right)\right\} \\
& +\frac{1}{R_{z}}\left(\frac{1}{R_{0}}+\frac{1}{R_{z}}-g_{m_{2}} \beta^{+}\right)+\frac{\beta^{+} g_{m_{1}}}{R_{0}}=0
\end{aligned}
$$

CO:

$$
\left\{\left(C_{1}+C_{z}\right)\left(\frac{1}{R_{0}}+\frac{1}{R_{z}}-g_{m_{2}} \beta^{+}\right)+\frac{1}{R_{z}}\left(C_{2}+C_{z}\right)\right\} \leq 0
$$

FO:

$$
\omega_{0}=\sqrt{\frac{R_{0}+R_{z}-R_{0} R_{z} g_{m_{2}} \beta^{+}+R_{z}^{2} \beta^{+} g_{m_{1}}}{R_{0} R_{z}^{2}\left(C_{1}+C_{z}\right)\left(C_{2}+C_{z}\right)}} .
$$

The passive and active sensitivities can be expressed as:

$$
S_{C_{1}}^{\omega_{0}}=-\frac{1}{2} \frac{C_{1}}{C_{1}+C_{z}}, \quad S_{C_{2}}^{\omega_{0}}=-\frac{1}{2} \frac{C_{2}}{C_{2}+C_{z}}, \quad S_{C_{z}}^{\omega_{0}}=-\frac{1}{2}\left(\frac{1}{C_{1}+C_{z}}+\frac{1}{C_{2}+C_{z}}\right) C_{z}(8 \mathrm{a})
$$




$$
\begin{gathered}
S_{\beta^{+}}^{\omega_{0}}=-\frac{1}{2} \frac{\beta^{+} R_{z}\left(R_{0} g_{m_{2}}-R_{z} g_{m_{1}}\right)}{R_{0}+R_{z}-R_{0} R_{z} g_{m_{2}} \beta^{+}+R_{z}^{2} \beta^{+} g_{m_{1}}}, \\
S_{g_{m_{1}}}^{\omega_{0}}=\frac{1}{2} \frac{R_{z}^{2} \beta^{+} g_{m_{1}}}{R_{0}+R_{z}-R_{0} R_{z} g_{m_{2}} \beta^{+}+R_{z}^{2} \beta^{+} g_{m_{1}}} \\
S_{g_{m_{2}}}^{\omega_{0}}=-\frac{1}{2} \frac{R_{0} R_{z} g_{m_{2}} \beta^{+}}{R_{0}+R_{z}-R_{0} R_{z} g_{m_{2}} \beta^{+}+R_{z}^{2} \beta^{+} g_{m_{1}}}, \\
S_{R_{0}}^{\omega_{0}}=-\frac{1}{2} \frac{R_{z}\left(1+R_{z} \beta^{+} g_{m_{1}}\right)}{R_{0}+R_{z}-R_{0} R_{z} g_{m_{2}} \beta^{+}+R_{z}^{2} \beta^{+} g_{m_{1}}} \\
S_{R_{z}}^{\omega_{0}}=-\frac{1}{2}\left(1+\frac{2 R_{0}+R_{z}}{R_{z}+R_{0}-R_{0} R_{z} \beta^{+} g_{m_{2}}+R_{z}^{2} \beta^{+} g_{m_{1}}}\right)
\end{gathered}
$$

In the ideal case, the various sensitivities of $\omega_{0}$ with respect to $C_{1}, C_{2}, R_{0}, C_{z}, R_{z}$, $g_{m 1}, g_{m 2}$ and $\beta^{+}$are found to be

$$
S_{C_{1}}^{\omega_{0}}=S_{C_{2}}^{\omega_{0}}=S_{R_{0}}^{\omega_{0}}=S_{R_{z}}^{\omega_{0}}=-\frac{1}{2}, S_{g_{m_{1}}}^{\omega_{0}}=S_{\beta^{+}}^{\omega_{0}}=\frac{1}{2}, S_{C_{z}}^{\omega_{0}}=S_{g_{m_{2}}}^{\omega_{0}}=0 .
$$

Considering the typical values of various parasitic e.g. $C_{z}=0.81 \mathrm{pF}, R_{\mathrm{z}}=53$ $\mathrm{k} \Omega, \beta^{+}=\beta^{-}=1$ along with $g_{m 1}=310.477 \mu \mho, g_{m 2}=291.186 \mu \mho, C_{1}=C_{2}=10 \mathrm{nF}$, and $R_{0}=4 \mathrm{k} \Omega$, the various sensitivities are found to be $S_{C_{1}}^{\omega_{0}}=-0.006$, $S_{C_{2}}^{\omega_{0}}=-0.006, \quad S_{C_{Z}}^{\omega_{0}}=-0.987, \quad S_{R_{0}}^{\omega_{0}}=-0.533, S_{R_{Z}}^{\omega_{0}}=-0.535, \quad S_{g_{m_{1}}}^{\omega_{0}}=0.502$, $S_{g_{m_{2}}}^{\omega_{0}}=-0.0355$, and $S_{\beta^{+}}^{\omega_{0}}=0.466$ which are all quite low.

\section{Frequency Stability}

Frequency stability is an important figure of merit of an oscillator. The frequency stability factor is defined as $S^{F}=\mathrm{d} \varphi(u) / \mathrm{d} u$, where $\omega / \omega_{0}$ is the normalized frequency, and $u=\varphi(u)$ represents the phase function of the open loop transfer function of the oscillator circuit. With $C_{1}=C_{2}=C, R_{0}=1 / g_{m 2}=1 / g, g_{m 1}=n g$, $S^{F}$ for the proposed SECO is found to be:

$$
S^{F}=2 \sqrt{n} .
$$

Thus, the new proposed configuration offers very high frequency stability factor larger values of $n$.

\section{Simulation Results}

The proposed QSO was simulated using CMOS VD-DIBA (as shown in Figure 3 ) to verify its theoretical analysis. The passive elements are selected as $R_{0}=4$ $\mathrm{k} \Omega$, and $C_{1}=C_{2}=10 \mathrm{nF}$. The transconductances of VD-DIBAs were controlled by bias voltages $V_{B 1}, V_{B 2}$ respectively. The simulated output waveforms for transient response and steady state response are shown in Figure 4 and Figure 5 respectively. These results, thus, confirm the validity of the proposed structure. Figure 6 shows the simulation results of the output spectrum, where the total harmonic distortion (THD) is found to be about $1.9 \%$ for both outputs $V_{o 1}$ and $V_{o 2}$. The generated waveforms relationship within quadrature circuit has been confirmed by Lissajous pattern shown in Figure 7. The CMOS VD-DIBA is 


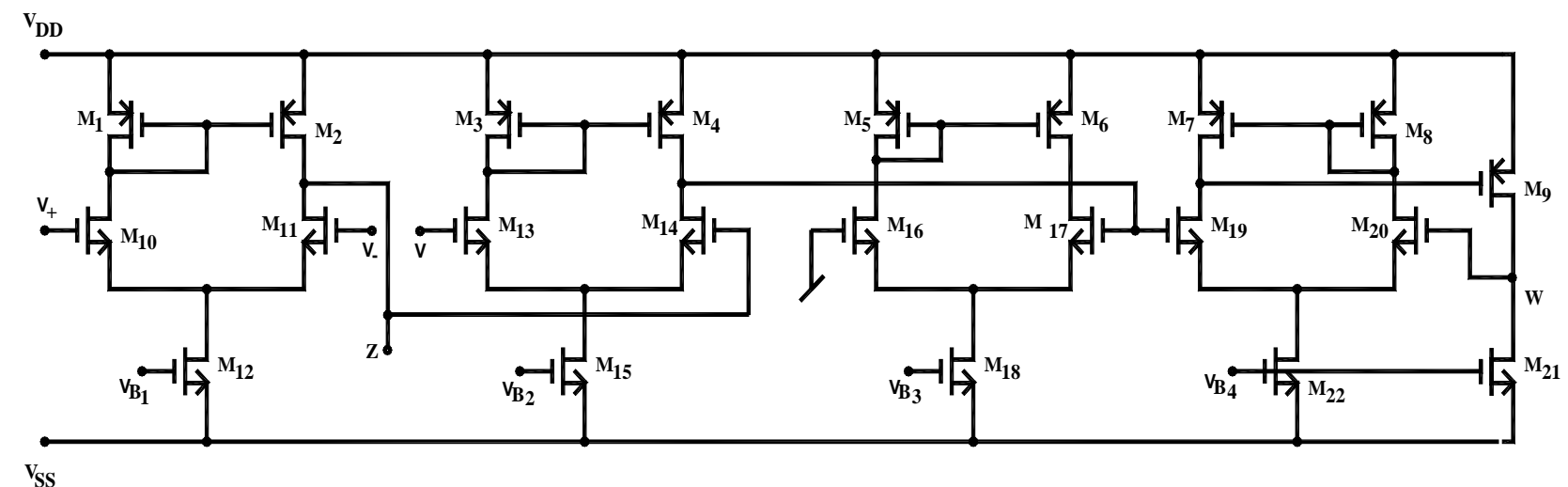

Figure 3. A CMOS transistor implementation of VD-DIBA, $V_{B 2}=V_{B 3}=-0.22 \mathrm{~V}$ and $V_{B 4}=-0.9 \mathrm{~V}, V_{D D}=-V_{S S}=2 \mathrm{~V}[16]$.

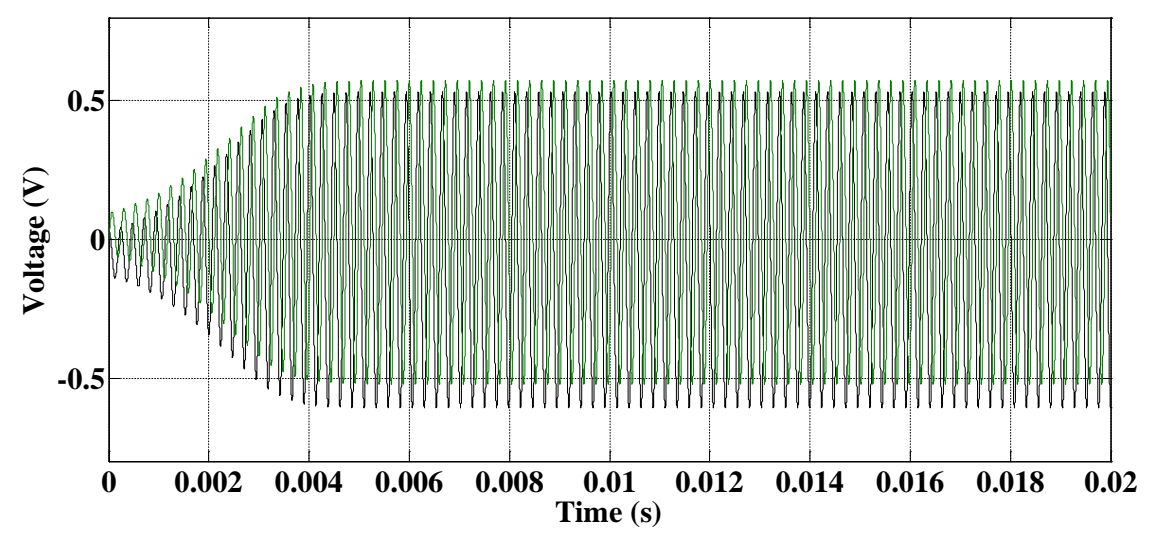

Figure 4. Transient response of proposed QSO.

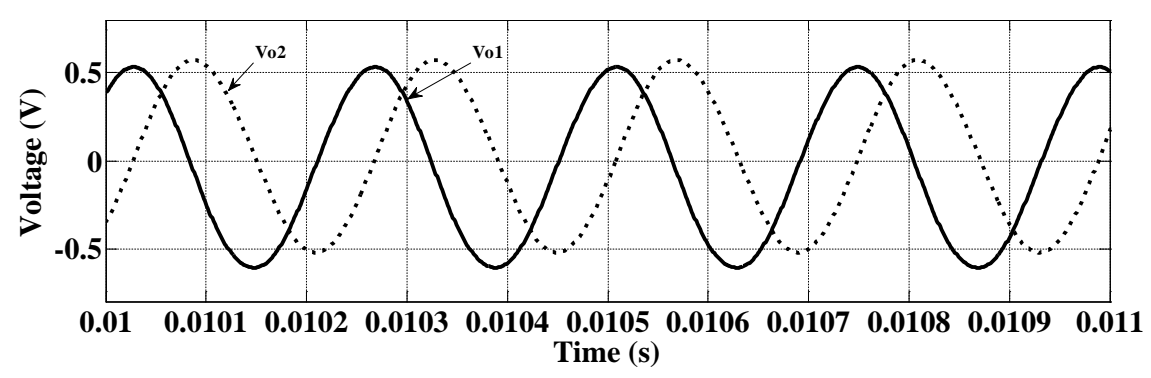

Figure 5. Steady state response of proposed QSO.

implemented using $0.35 \mu \mathrm{m}$ MIETEC technology. The transistor model parameters used for CMOS VD-DIBA are listed in Table 1 and aspect ratios (W/L ratios) of the MOSFETs used in Figure 3 are shown in Table 2. Comparisons of previously known quadrature sinusoidal oscillators are Table 3.

\section{Conclusion}

In this communication, an electronically tunable voltage-mode quadrature sinusoidal oscillator enabling independent electronic control of frequency of oscillation and condition of oscillation is presented. The proposed QSO circuit employs only two VD-DIBAs, two grounded capacitors and a resistor. The 


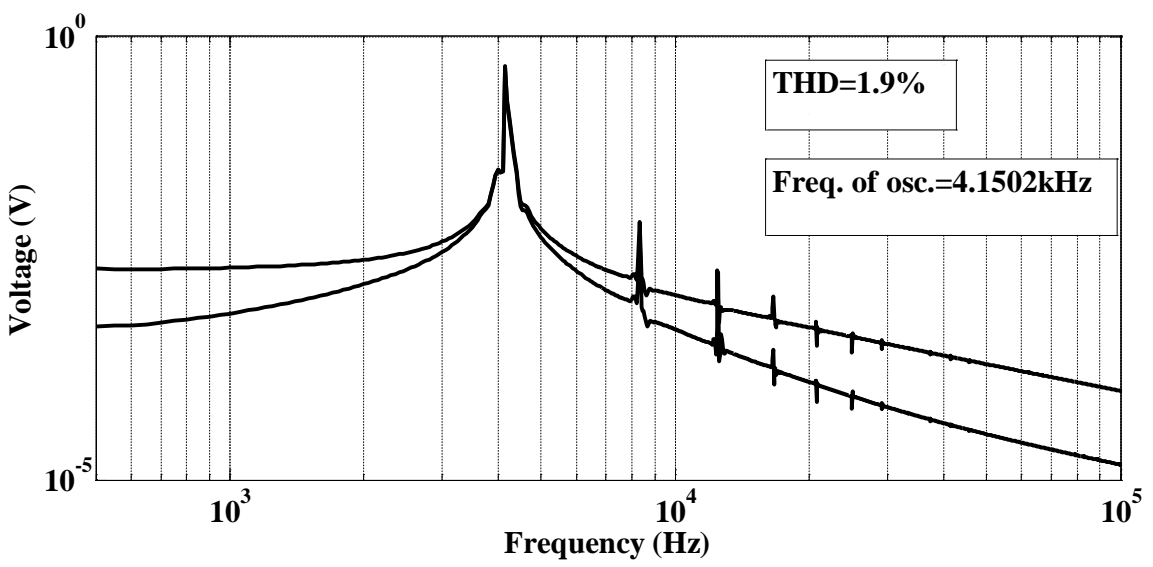

Figure 6. Frequency response of proposed QSO.

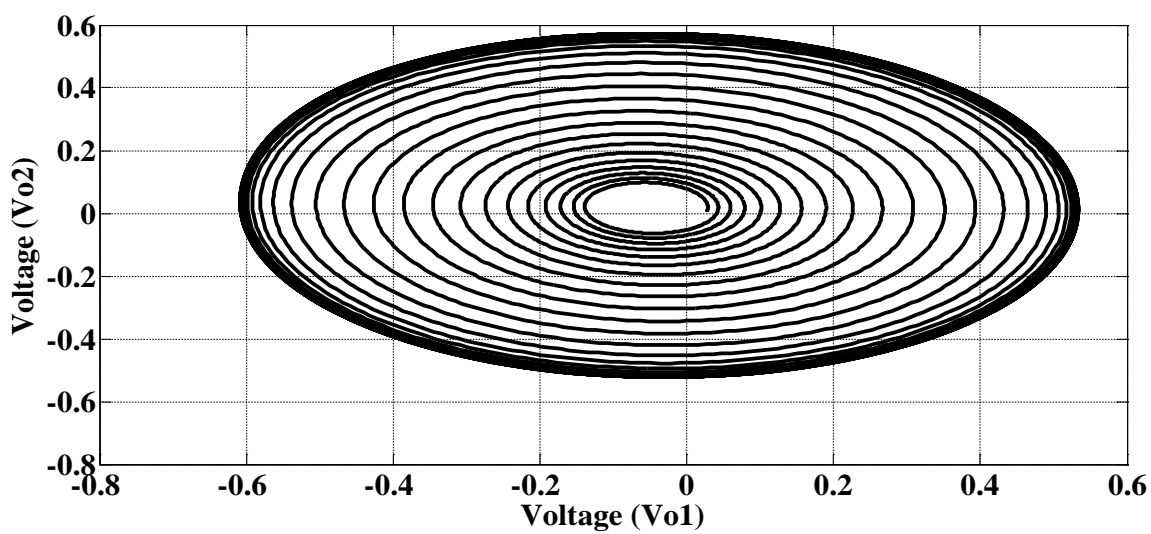

Figure 7. Lissajous pattern of proposed QSO.

Table 1. Transistors process parameters in SPICE simulations.

. MODEL N NMOS $($ LEVEL $=3 ;$ TOX $=7.9 \mathrm{E}-9 ;$ NSUB $=1$ E17; GAMMA $=0.5827871 ;$ PHI $=0.7$; $\mathrm{VTO}=0.5445549 ;$ DELTA $=0 ; \mathrm{UO}=436.256147 ; \mathrm{ETA}=0 ;$ THETA $=0.1749684 ; \mathrm{KP}=$ $2.055786 \mathrm{E}-4$; VMAX $=8.309444 \mathrm{E} 4$; KAPPA $=0.2574081 ; \mathrm{RSH}=0.0559398 ; \mathrm{NFS}=1 \mathrm{E} 12 ;$ TPG $=1$; $\mathrm{XJ}=3 \mathrm{E}-7 ; \mathrm{LD}=3.162278 \mathrm{E}-11 ; \mathrm{WD}=7.046724 \mathrm{E}-8 ; \mathrm{CGDO}=2.82 \mathrm{E}-10 ; \mathrm{CGSO}=2.82 \mathrm{E}-10$ $\mathrm{CGBO}=1 \mathrm{E}-10 ; \mathrm{CJ}=1 \mathrm{E}-3 ; \mathrm{PB}=0.9758533 ; \mathrm{MJ}=0.3448504 ; \mathrm{CJSW} ;=3.777852 \mathrm{E}-1 ; \mathrm{MJSW}=$ $0.3508721)$

.MODEL P PMOS $($ LEVEL $=3 ;$ TOX $=7.9 \mathrm{E}-9 ;$ NSUB $=1 \mathrm{E} 17 ;$ GAMMA $=0.4083894 ;$ PHI $=0.7$; $\mathrm{VTO}=-0.7140674 ; \mathrm{DELTA}=0 ; \mathrm{UO}=212.2319801 ; \mathrm{ETA}=9.999762 \mathrm{E}-4 ; \mathrm{THETA}=0.2020774 ; \mathrm{KP}$ $=6.733755 \mathrm{E}-5 ; \mathrm{VMAX}=1.181551 \mathrm{E} 5 ; \mathrm{KAPPA}=1.5 ; \mathrm{RSH}=30.0712458 ; \mathrm{NFS}=1 \mathrm{E} 12 ; \mathrm{TPG}=-1$; $\mathrm{XJ}=2 \mathrm{E}-7 ; \mathrm{LD}=5.000001 \mathrm{E}-13 ; \mathrm{WD}=1.249872 \mathrm{E}-7 ; \mathrm{CGDO}=3.09 \mathrm{E}-10 ; \mathrm{CGSO}=3.09 \mathrm{E}-10 ; \mathrm{CGBO}$ $=1 \mathrm{E}-10 ; \mathrm{CJ}=1.419508 \mathrm{E}-3 ; \mathrm{PB}=0.8152753 ; \mathrm{MJ}=0.5 ; \mathrm{CJSW}=4.813504 \mathrm{E}-10 ; \mathrm{MJSW}=0.5$ )

Table 2. Aspect ratios of CMOS transistors used in Figure 3.

\begin{tabular}{cc}
\hline Transistor & $\mathrm{W} / \mathrm{L}(\mu \mathrm{m})$ \\
\hline M1 - M6 & $14 / 1$ \\
M7 - M9 & $14 / 0.35$ \\
M10 - M18 & $4 / 1$ \\
M19 - M22 & $7 / 0.35$
\end{tabular}


Table 3. Comparison of previously known quadrature sinusoidal oscillators.

\begin{tabular}{cccccc}
\hline \multirow{2}{*}{ Reference } & Active Elements & \multicolumn{2}{c}{ No. of Passive Components } & \multicolumn{2}{c}{ Electronic Controllability of: } \\
\cline { 3 - 6 } & & $\begin{array}{c}\text { No. of } \\
\text { Grounded C }\end{array}$ & $\begin{array}{c}\text { No. of } \\
\text { C + R }\end{array}$ & CO & FO \\
\hline$[18]$ & 2 VD - DIBA + UGC & 2 & $0+0$ & NO & YES \\
{$[19]$} & 2CDBA & 1 & $1+3$ & NO & NO \\
{$[20]$} & 2OTRA & 2 & $0+4$ & NO & NO \\
{$[21]$} & 2CDBA & 2 & $0+3$ & NO & NO \\
{$[22]$} & 2 VDIBA + 2MOS & 1 & $1+0$ & YES & YES \\
{$[23]$} & 3CFTA & 2 & $0+0$ & YES & YES \\
proposed & 2 VD - DIBA & 2 & $0+1$ & YES & YES \\
\hline
\end{tabular}

proposed QSO is capable of simultaneously providing two explicit quadrature voltage outputs. The condition of oscillation and the frequency of oscillation of the proposed circuit are controllable electronically through separate transconductance of the VD-DIBAs. The workability of the proposed structure has been demonstrated by PSPICE simulations using $0.35 \mu \mathrm{m}$ MIETEC technology.

\section{References}

[1] Horng, J.W., Hou, C.L., Chang, C.M., Chung, W.Y., Tang, H.W. and Wen, Y.H. (2005) Quadrature Oscillators Using CCIIs. International Journal of Electronics, 92, 21-31. https://doi.org/10.1080/00207210412331332899

[2] Gibson, J.D. (1997) The Communication Handbook. CRC Press, Boca Raton.

[3] Tangsrirat, W. and Surakampontorn, W. (2009) Single-Resistance Controlled Quadrature Oscillator and Universal Biquad Filter Using CFOAs. AEU-International Journal of Electronics and Communications, 63, 1080-1086. https://doi.org/10.1016/j.aeue.2008.08.006

[4] Horng, J.W. (2002) Current Differencing Buffered Amplifiers Based Single Resistance Controlled Quadrature Oscillator Employing Grounded Capacitors. IEICE Transactions on Fundamentals of Electronics, Communications and Computer Sciences, E85-A, 1416-1419.

[5] Ozcan, S., Toker, A., Acar, C., Kuntman, H. and Cicekoglu, O. (2000) Single Resistance-Controlled Sinusoidal Oscillators Employing Current Differencing Buffered Amplifier. Microelectronics Journal, 31, 169-174. https://doi.org/10.1016/S0026-2692(99)00113-5

[6] Prommee, P. and Dejhan, K. (2002) An Integrable Electronic Controlled Quadrature Sinusoidal Oscillator Using CMOS Operational Transconductance Amplifier. International Journal of Electronics, 89, 365-379. https://doi.org/10.1080/713810385

[7] Rodriguez-Vazquez, A., Linares-Barranco, B., Huertas, J.L. and Sanchez-Sinencio, E. (1990) On the Design of Voltage Controlled Sinusoidal Oscillators Using OTA's. IEEE Transactions on Circuits and Systems, 37, 198-211. https://doi.org/10.1109/31.45712

[8] Holzel, R. (1993) A Simple Wide-Band Sine Wave Quadrature Oscillator. IEEE Transactions on Instrumentation and Measurement, 42, 758-760. https://doi.org/10.1109/19.231604 
[9] Biolek, D., Senani, R., Biolkova, V. and Kolka, Z. (2008) Active Elements for Analog signal processing: Classification, Review, and New Proposals. Radioengineering, 17, 15-32.

[10] Pushkar, K.L., Goel, R.K., Gupta, K., et al. (2016) New VD-DIBA-Based Single-Resistance-Controlled Sinusoidal Oscillator. Circuits and Systems, 7, 4145-4153.

[11] Prasad, D., Bhaskar, D.R. and Pushkar, K.L. (2013) Electronically Controllable Sinusoidal Oscillator Employing CMOS VD-DIBAs. ISRN Electronics, 2013, Article ID: 823630 .

[12] Pushkar, K.L., Bhaskar, D.R. and Prasad, D. (2013) Single-Resistance Controlled Sinusoidal Oscillator Using Single VD-DIBA. Active and Passive Electronic Components, 2013, Article ID: 971936. https://doi.org/10.1155/2013/971936

[13] Bhaskar, D.R. Prasad, D. and Pushkar, K.L. (2013) Fully Uncoupled Electronically Controllable Sinusoidal Oscillator Employing VD-DIBAs. Circuits and Systems, 4, 264-268. https://doi.org/10.4236/cs.2013.43035

[14] Pushkar, K.L., Bhaskar, D.R. and Prasad, D. (2013) A New MISO-Type Voltage-Mode Universal Biquad Using Single VD-DIBA. ISRN Electronics, 2013, Article ID: 478213.

[15] Pushkar, K.L., Bhaskar, D.R. and Prasad, D. (2013) Voltage-Mode Universal Biquad Filter Employing Single VD-DIBA. Circuits and Systems, 4, 44-48. https://doi.org/10.4236/cs.2013.41008

[16] Prasad, D., Bhaskar, D.R. and Pushkar, K.L. (2011) Realization of New Electronically Controllable Grounded and Floating Simulated Inductance Circuits using Voltage Differencing Differential Input Buffered Amplifiers. Active and Passive Electronic Components, 2011, Article ID: 101432.

[17] Bhaskar, D.R., Prasad, D. and Pushkar, K.L. (2013) Electronically-Controllable Grounded-Capacitor-Based Grounded and Floating Inductance Simulated Circuits using VD-DIBAs. Circuits and Systems, 4, 422-430. https://doi.org/10.4236/cs.2013.45055

[18] Bajer, J., Vavra, J. and Biolek, D. (2014) Voltage-Mode Quadrature Oscillator Using VD-DIBA Active Elements. IEEE Asia Pacific Conference on Circuits and Systems, Ishigaki, 17-20 November 2014, Vol. 4, 197-200. https://doi.org/10.1109/APCCAS.2014.7032755

[19] Kalra, D., Gupta, S. and Arora, T.S. (2016) Single-Resistance Controlled Quadrature Oscillator Employing Two Current Differencing Buffered Amplifier. 2nd International Conference on Contemporary Computing and Informatics, Noida, 14-17 December 2016, 688-692.

[20] Pittala, C.S. and Srinivasulu, A. (2015) Quadrature Oscillator Using Operational Transresistance Amplifier. International Conference on Applied Electronics, Pilsen, 9-10 September 2014, 117-128.

[21] Tangsrirat, W., Prasertsom, D., Piyatat, T. and Surakampontorn, W. (2008) Single-Resistance-Controlled Quadrature Oscillator using Current Differencing Buffered Amplifiers. International Journal of Electronics, 95, 1119-1126. https://doi.org/10.1080/00207210802387676

[22] Channumsin, O. and Tangsrirat, W. (2017) VDIBA-Based Sinusoidal Quadrature Oscillator. Przglad Elektrotechniczny, 93, 248-251.

[23] Phatsornsiri, P. and Lamun, P. (2015) Tunable Current-Mode Quadrature Oscillator using CFTAs and Grounded Capacitors. 12 th International Conference on Electrical Engineering/Electronics, Computer, Telecommunications and Information Technology, Hua Hin, 24-27 June 2015, 1-4.

https://doi.org/10.1109/ECTICon.2015.7207104 